Sharif University of Technology
Scientia Iranica
SCIENTIA
IRAN I CA

\title{
Effect of deep sub-zero treatment on mechanical properties of AA5XXX aluminum plates adjoined by MIG welding technique
}

\author{
H. Ates ${ }^{\mathrm{a}, *}$, A. Tamer Özdemir ${ }^{\mathrm{a}}, \mathrm{M} \cdot \mathrm{Uzun}^{\mathrm{b}}$ and I. Uygur \\ a. Department of Metallurgical and Materials Engineering, Faculty of Technology, Gazi University, 06500 Teknikokullar, Ankara, \\ Turkey. \\ b. Department of Metallurgical and Materials Engineering, Graduate School of Science and Technology, Gazi University, 06500 \\ Teknikokullar, Ankara, Turkey. \\ c. Department of Mechanical Engineering, Faculty of Engineering, Duzce University, Duzce, Turkey.
}

Received 17 June 2015; received in revised form 9 March 2016; accepted 13 August 2016

\section{KEYWORDS}

Aluminum alloy; Sub-zero treatment; MIG welding.

\begin{abstract}
In this study, mechanical and microstructural characteristics of AA5XXX aluminum plates connected by MIG welding were investigated. Thus, after several preliminary experiments done to ensure quality requirements of the parameters, specimens in the form of long aluminum plates were welded, and then some of them were spared for the subsequent sub-zero treatment at about $146^{\circ} \mathrm{C}$ for 12 and $24 \mathrm{~h}$, respectively. To investigate the effect of this super cooling on the welded parts, several tensile, bending, and hardness tests in conjunction with micro-structure examinations were carried out and results were discussed in detail. It was concluded that during sub-zero treatment, microstructure gets finer and stabilized, positively affecting the overall strength of the material. There is no significant difference in the overall strength of the material right after the subzero treatment and that of the specimens rested for one year at room temperature after cryogenics treatments.

(C) 2017 Sharif University of Technology. All rights reserved.
\end{abstract}

\section{Introduction}

Aluminum and its alloys are commonly used in various industrial and structural engineering applications due to their low density and high strength-to-weight ratio. Various types of Al-alloys were extensively studied in terms of joining [1-4]. Aluminum is one of the most abundant elements on the earth's crust, started to be used commonly at the end of the 19th century in engineering applications. Currently, aluminum alloys are

*. Corresponding author.

E-mail addresses: hates@gazi.edu.tr (H. Ates);

tozdemir@gazi.edu.tr (A. Tamer Özdemir);

omerrua@gmail.com (M. Uzun); ilyasuygur@duzce.edu.tr (I. Uygur) used in high-tech fields such as electronics, automobile, transportation, sporting goods, and aerospace industries [5]. Today, value and usage of these materials are effectively classified according to their possibility of welding and joining capability and giving long service lives [6-10].

Cryogenic treatment is a supplementary process for conventional heat treatment. Unlike the outcomes of conventional surface treatments, it is an inexpensive treatment that affects both the core structure and properties of the components. More than three decades, studies on cryogenic impacts, particularly for the behavior of tool steels have been done seriously. But so far, very little knowledge exists on how cryogenics affects non-ferrous materials such as aluminum. However, literature survey commonly reveals 
that mechanical strength of materials mostly increases significantly after being submitted to several cycles of subzero treatments [11-14].

Aluminum Alloy (AA) 5083 is the marine-grade alloy used in the construction of passenger, freight, and naval containers. Owing to the demanding nature of the service conditions and environments in which marine vessels operate, welded components and structures are susceptible to high level of loads, which may cause micro-structural degrade and final catastrophic failure. As a necessity of using tremendous amount of aluminum alloys in ship construction industry, a great deal of research has been carried out focusing on the longterm performance of the welded joints [15-17]. There are only a few papers examining the microstructural changes that result in the failure of the joint which is mostly introduced during the process of welding [18]. AA5083 alloy is preferred in many applications due to its acceptable grade of weldability, strength, and high corrosion resistance. However, welding of such alloys after severe strain hardening mostly results in substantial reduction of strength in the Heat Affected Zone (HAZ) [19]. Decrease in strength is unavoidable, but special care should be taken to avoid welding defects that may further reduce the overall strength of the material. Thus, possible defects have to be inspected routinely in the vicinity of the weldment, repairing the weldment can be usually employed to extend service life of the component. Despite wide application of the present alloy and interest in improving its properties by additional alloying, there is still a lack of detailed mechanical characterization of this material and study of the effect of subsequent cryogenic treatment on its microstructure. Thus, in this study, the MIG welded samples of AA5083 alloy were soaked at $-146^{\circ} \mathrm{C}$ for $12 \mathrm{~h}$ and $24 \mathrm{~h}$, and then rested at room temperature for a while before investigating the microstructure, hardness, bending, and tensile properties of the metal products.

On the other hand, after the cryogenic treatments, some samples were kept at room temperature on purpose for about a year to check the stability of the mechanical strength and how the material stands for such a long time.

\section{Experimental work and materials}

\subsection{Materials}

AA5083 aluminum alloy was chosen for studying the effect of cryogenic treatment. The chemical composition of the samples $\left(5 \times 500 \times 1000 \mathrm{~mm}^{3}\right.$ in dimension $)$ analyzed by a vacuum spectrometer is presented in Table 1. AA5336 (AlMg5Cr) wire as a filler material was used for the joining processes, where chemical composition of the filler is also given in Table 1 . On the other hand, tensile properties of these materials are listed in Table 2.

\subsection{Sample preparation and experimental details}

Pre-welding cleaning procedures (oxide, stain, oil, and dirt removing) along with the steps taken to protect the molten weld zone were carried out to avoid contamination of the weld. A schematic diagram of the welded test plate and its welding consequence is shown in Figure 1. The plate was $5 \mathrm{~mm}$ thick, and therefore double-welding passes were deposited. The welds were produced using the $\mathrm{ESAB}^{\mathrm{TM}} 400$ type of semi-automatic welding machine. All the samples were obtained in the same orientation from flat position. During welding all parameters such as welding voltage and current, wire speeds, gas flow, and heat inputs

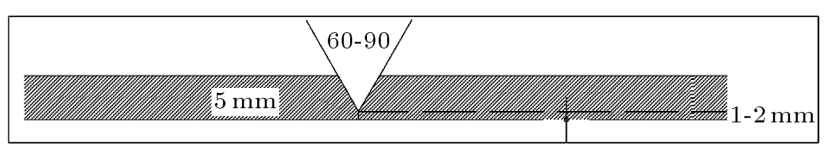

(a)

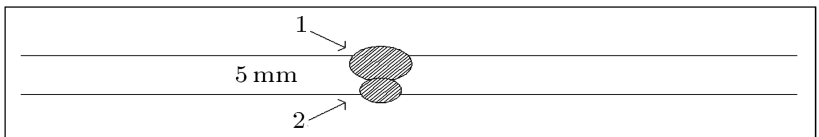

(b)

Figure 1. Schematic illustration of (a) grove and (b) welding sequence $\left(60-90^{\circ}\right)$.

Table 1. Chemical composition of base and filler materials.

\begin{tabular}{cccccccccc}
\hline Materials & $\mathbf{S i}$ & $\mathbf{F e}$ & $\mathbf{C u}$ & $\mathbf{M n}$ & $\mathbf{M g}$ & $\mathbf{C r}$ & $\mathbf{Z n}$ & $\mathbf{T i}$ & Al \\
\hline AA5083 & 0.12 & 0.243 & 0.073 & 0.489 & 4.85 & 0.108 & 0.075 & 0.035 & Bal. \\
AA5356 & 5 & 0.4 & 0.1 & 0.5 & 0.1 & 0.1 & 0.1 & 0.15 & Bal. \\
\hline
\end{tabular}

Table 2. Tensile properties of the materials.

\begin{tabular}{cccc}
\hline Materials & $\begin{array}{c}\text { Yield strength } \\
\left(\boldsymbol{\sigma}_{\boldsymbol{\%} \mathbf{0 . 2}}\right), \mathbf{M P a}\end{array}$ & $\begin{array}{c}\text { Ultimate tensile } \\
\text { strength }\end{array}$ & $\begin{array}{c}\text { Elongation, } \\
\left.\boldsymbol{\sigma}_{\mathrm{UTS}}\right), \mathbf{M P a}\end{array}$ \\
\hline AA5083 & 220 & 305 & $\%$ \\
AA5356 & 250 & 310 & 22 \\
\hline
\end{tabular}


Table 3. Details of the welding process variables.

\begin{tabular}{ccccccc}
\hline Pass & $\begin{array}{c}\text { Wire diameter } \\
(\mathbf{m m})\end{array}$ & $\begin{array}{c}\text { Current }(\mathbf{A}) / \\
\text { voltage }(\mathbf{V})\end{array}$ & $\begin{array}{c}\text { Gas flow } \\
(\mathbf{l t} / \mathbf{m i n})\end{array}$ & $\begin{array}{c}\text { Torch angle } \\
\left({ }^{\circ}\right)\end{array}$ & $\begin{array}{c}\text { Wire speed } \\
(\mathbf{m m} / \mathbf{m i n})\end{array}$ & $\begin{array}{c}\text { Heat input } \\
\left(\boldsymbol{k}_{\boldsymbol{j}} / \mathbf{m m}\right)\end{array}$ \\
\hline 1 & 1.2 & $155-170 / 22.8-23.5$ & 15 & $75-85$ & $450-550$ & $0.31-0.43$ \\
2 & 1.2 & $155-170 / 22.8-23.5$ & 15 & $75-85$ & $450-550$ & $0.31-0.43$ \\
\hline
\end{tabular}

were measured. The welding machine characteristics and other parameters are given in Table 3.

Argon with a high rate of purity (\%99.9) was used as a shielding gas during welding to prevent absorption of oxygen, hydrogen, and nitrogen from the atmosphere. Arc gap between the work piece and torch is $10-20 \mathrm{~mm}$ and the temperature between the passes is $120^{\circ} \mathrm{C}$. Finally, cryogenic treatment was carried out in a nitrogen cryo-bath $\left(-146^{\circ} \mathrm{C}\right)$ where the samples were soaked at that temperature for $12 \mathrm{~h}$ and $24 \mathrm{~h}$. This regime of treatment is mostly preferred in the industry and most data available in the literature are listed for about this deep cryogenic level.

Samples were prepared according to EN 288-4 (TS EN ISO 15641-2) welding standards. Cutting process was made by water jet to avoid the interaction between heat and microstructure. Tensile test (TS EN ISO 4136) and bending tests (TS EN ISO 5173) were performed at room temperature and six samples were used for each condition. An average of these tests was presented in this study. Tensile tests were carried out by Instron MLF-type device of $60 \mathrm{kN}$ capacity at a speed of $0.5 \mathrm{~mm} / \mathrm{min}$.

\subsection{Metallography}

$5 \times 25 \times 75 \mathrm{~mm}^{3}$ samples were sectioned transversely into the weld direction for microstructural characterization and hardness measurements. A metallographic technique (ASTM E3-01 standard) was employed in grinding with various grades of $\mathrm{SiC}$ papers (i.e., 3201200 meshes) followed by polishing using $3 \mu \mathrm{m}$ and
$1 \mu \mathrm{m}$ diamond grits. Samples were etched in the Keller's modified solution. The microstructure of samples was investigated by Nikon Eclipse LV 150 optical microscopy.

\subsection{Hardness}

Vickers micro-hardness measurements were taken from the center of the weld metal towards left and right sides by passing through HAZ to the base metal in the depth of $2 \mathrm{~mm}$ from the welding surface by using Instron micro-hardness tester with a load of $500 \mathrm{~g}$.

\section{Results and discussion}

\subsection{Tensile test results}

Test results of Un-Treated (UT), 12 h Cryogenically Treated (12 h CT), and $24 \mathrm{~h}$ Cryogenically Treated (24 h CT) AA5083 samples are given in Table 4a, respectively.

As seen in Table 4, the yield strength, UTS, and elongation of untreated sample are lower than those of $12 \mathrm{~h} \mathrm{CT}$ and $24 \mathrm{~h}$ CT samples. Compared to UT samples, yield strength of CT piece increases in $12 \%$, ultimate tensile strength by $14 \%$, and elongation by $2 \%$, respectively. This can simply be attributed to the formation of ultra-fine microstructure and perfect penetration of the weldments. Similarly, it is obvious in Table $4 \mathrm{~b}$ that UTS and elongation of UT are lower than those of $12 \mathrm{~h}$ CT samples. According to the results, compared to UT samples, CT pieces have an increase in yield strength by $12 \%$, ultimate tensile strength by $14 \%$, and elongation by $2 \%$, respectively.

Table 4a. Tensile test results right after welding and cryonics process.

\begin{tabular}{cccc}
\hline Sample & $\begin{array}{c}\text { Yield strength } \\
\left(\boldsymbol{\sigma}_{\boldsymbol{\%} \mathbf{0 . 2}}\right), \mathbf{M P a}\end{array}$ & $\begin{array}{c}\text { Ultimate tensile } \\
\text { strength }\left(\boldsymbol{\sigma}_{\mathrm{UTS}}\right), \mathbf{M P a}\end{array}$ & $\begin{array}{c}\text { Elongation, } \\
\boldsymbol{\%}\end{array}$ \\
\hline UT & 200.12 & 297.1 & 21.12 \\
$12 \mathrm{~h} \mathrm{CT}$ & 264.13 & 296.22 & 23.85 \\
$24 \mathrm{~h} \mathrm{CT}$ & 294.44 & 392.24 & 23.99 \\
\hline
\end{tabular}

Table 4b. Tensile test results one year later after welding and cryonics process.

\begin{tabular}{cccc}
\hline Sample & $\begin{array}{c}\text { Yield strength } \\
\left(\boldsymbol{\sigma}_{\boldsymbol{\%} \mathbf{0 . 2}}\right), \mathbf{M P a}\end{array}$ & $\begin{array}{c}\text { Ultimate tensile } \\
\text { strength }\left(\boldsymbol{\sigma}_{\mathrm{UTS}}\right), \mathbf{M P a}\end{array}$ & $\begin{array}{c}\text { Elongation, } \\
\%\end{array}$ \\
\hline UT & 201.999 & 300.115 & 21.938 \\
$12 \mathrm{~h} \mathrm{CT}$ & 261.557 & 351.671 & 24.062 \\
$24 \mathrm{~h} \mathrm{CT}$ & 290.405 & 374.248 & 24.963 \\
\hline
\end{tabular}


Alternatively, the results obtained right after welding and cryogenics process give lower mechanical values at least $3 \%$ compared to the samples rested for one year after welding and sub-zero treatment. However, in this study, as a whole, maximum change between all these is about $10 \%$.

Similar to the above findings, several studies on the cryogenic evolution of welded samples claim that minor increases in both tensile strength and hardness are generally noticeable in weldments, particularly in the parent metal, such that after deep cryogenic treatment without sacrificing tensile strength, residual stresses mostly entrapped around the weldment can be released [20-23].

\subsection{Bending test results}

Typical photographs of bended samples after welding, such as UT, $12 \mathrm{~h} \mathrm{CT}$, and $24 \mathrm{~h} \mathrm{CT}$, are all presented in Figure 2. Because all the samples produced in this work are crack-free, bending characteristics can be mainly related to ductility of the material. Aluminum alloys are known as ductile materials. As can be noticed from Table 4, elongation values of welded samples are very similar.

\subsection{Microstructure of joints}

Typical macrostructures of the samples after welding, e.g. UT, $12 \mathrm{~h} \mathrm{CT}$, and $24 \mathrm{~h} \mathrm{CT}$, are given in Figure 3 , where microstructural details are particularly shown in Figures 4-6 for different regions. According to macro-examination, perfect bonding and sufficient penetration are obtained. However, porosities can be traced out at the end of the root (Figure 3(c)). Porosity is a general term describing cavities or pores caused by gas and/or nonmetallic material entrapment in molten metal during solidification. There are many causes which include contamination, inadequate

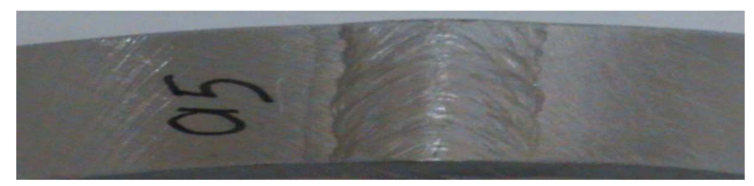

(a)

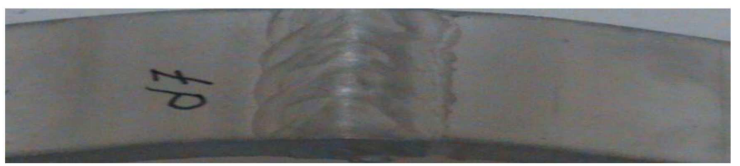

(b)

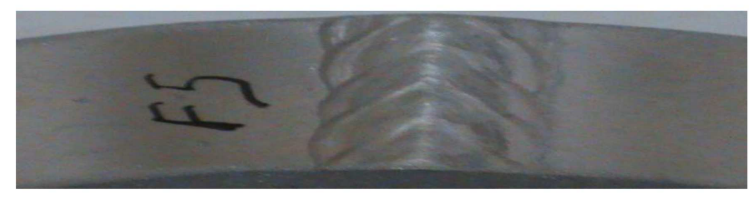

(c)

Figure 2. Samples after bending test: (a) Untreated (UT), (b) $12 \mathrm{~h} \mathrm{CT}$, and (c) $24 \mathrm{~h} \mathrm{CT}$.

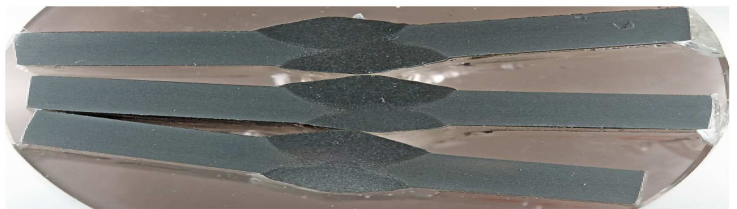

(a)

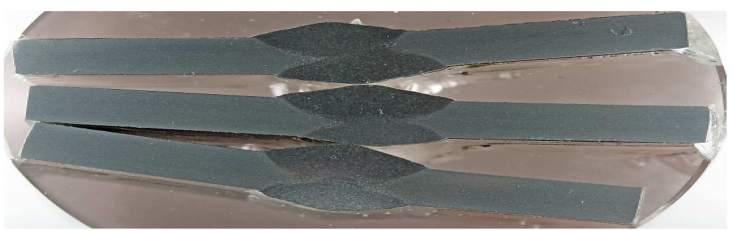

(b)

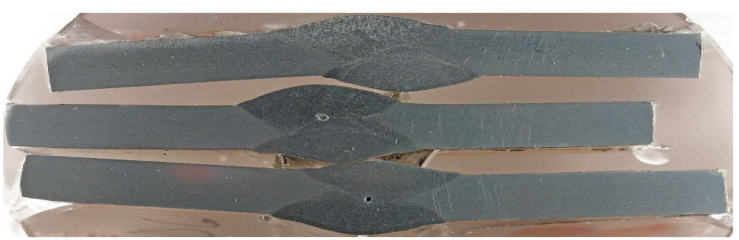

(c)

Figure 3. Macrostructures of (a) untreated (UT), (b) 12 $\mathrm{h} \mathrm{CT}$, and (c) $24 \mathrm{~h} \mathrm{CT}$.

shielding, unstable arc, short arc gap, and poor welding technique [24]. Although porosities are seen only in two samples, the rest are perfectly joined and defect-free. Thus, it can be claimed that correct parameters and good welding techniques have been adopted during the welding process.

Thus, Figures 4-6 show optical micro-graphs of welded AA5083-base metal with AA5356 filler metals. In the 5356 weld metals, dispersed and crystallized particles of several micrometers in size are observed. The composition analysis of the crystallized particles using EDS revealed that those of the base metal were mainly composed of $\mathrm{Al}, \mathrm{Fe}$, and $\mathrm{Mn}$, whereas those of the weld metals were mainly $\mathrm{Al}, \mathrm{Si}$, and $\mathrm{Mg}$. However, weld defects, such as blowholes and deposited metal cracking, were not detected by means of screening test

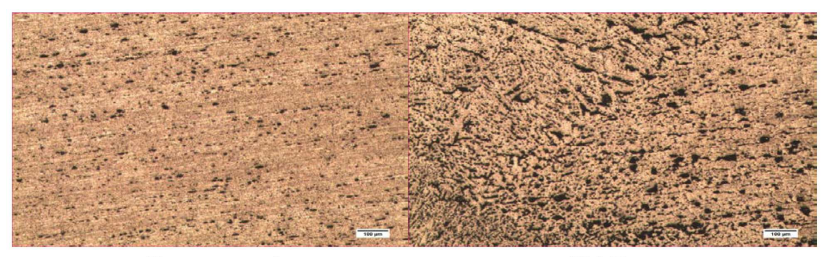

Base metal

HAZ

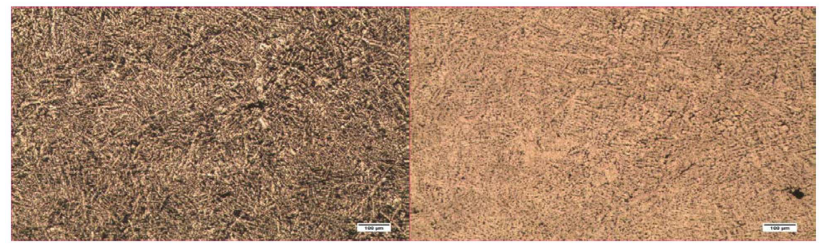

Lower pass

Upper pass

Figure 4. Micro-graphs of welded UT sample with different zones. 


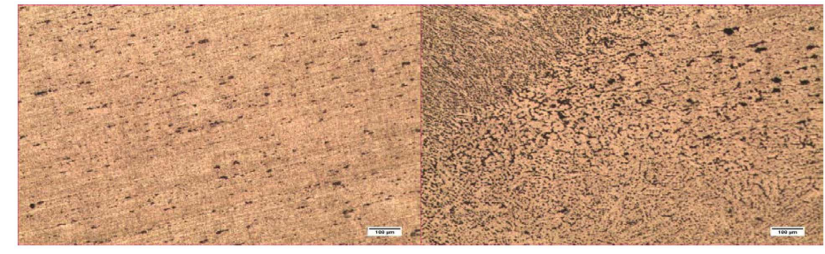

Base metal HAZ

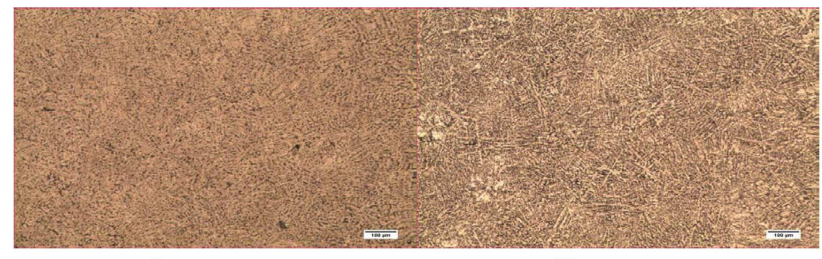

Lower pass

Upper pass

Figure 5. Micro-graph of welded 12 h CT sample with different zones.

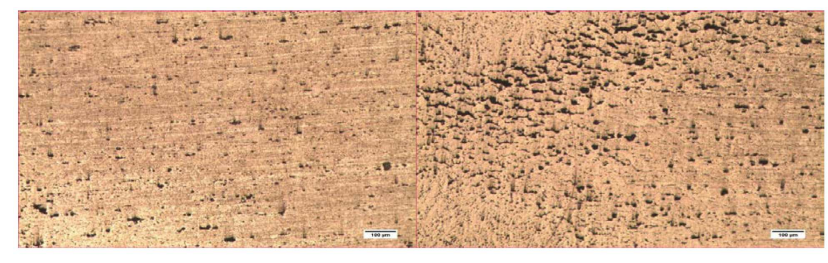

Base metal

HAZ

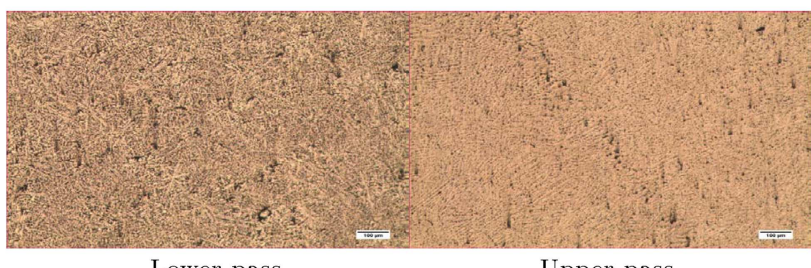

Lower pass

Upper pass

Figure 6. Micro-graph of welded $24 \mathrm{~h} \mathrm{CT}$ sample with different zones.

or microscopy in the weld metals. It is seen that better distribution of precipitates and particles is evident in these pictures (Figures 4-6). Cryogenic treatment significantly refined the microstructure. Though, these are just preliminary work, further studies need to be conducted to address the reasons for better microstructural and mechanical improvements. Thus, different phase transformation and uniform distribution of precipitation resulted in better mechanical responses of the material (i.e., tool steels) $[11,12,25]$.

\subsection{Hardness measurements}

The impact of cryogenic treatment on strength was studied via micro-hardness tests. Vicker's hardness measurements were taken as $1 \mathrm{~mm}$ intervals starting from both sides in going towards the weld centre. Results are presented in Figure 7. Hardness values on the fusion line are the highest, i.e. $72 \mathrm{HV}$ for $\mathrm{UT}, 87 \mathrm{HV}$ for $12 \mathrm{~h} \mathrm{CT}$, and $99 \mathrm{HV}$ for $24 \mathrm{~h} \mathrm{CT}$, respectively. It is apparent that hardness values and tensile properties are strongly affected by the sub-zero treatment (Table 4).

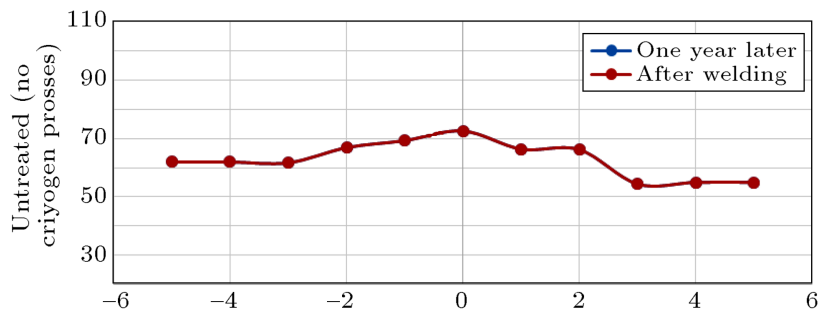

(a)

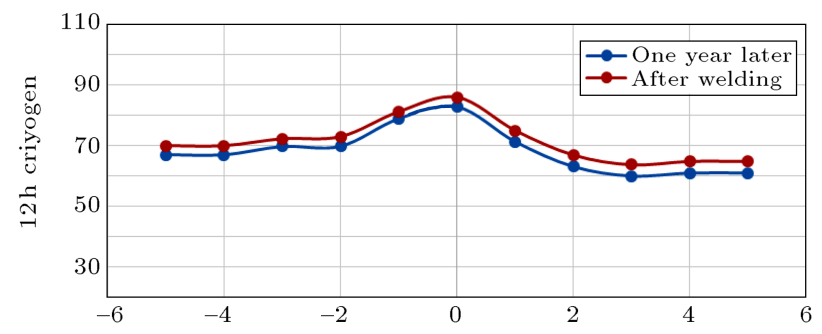

(b)

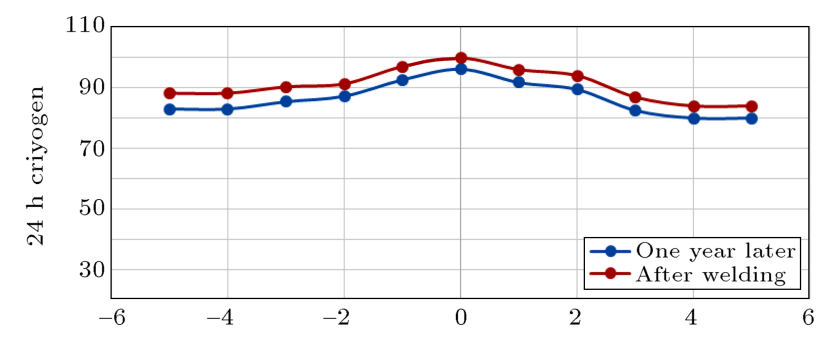

(c)

Figure 7. Micro-hardness distribution of welded samples after welding and one year later after welding cryogenics processes: (a) UT, (b) $12 \mathrm{~h} \mathrm{CT}$, and (c) $24 \mathrm{~h} \mathrm{CT}$.

Similarly, test has been conducted on several samples that were first tested at room temperature for about one year. It is noticeable that hardness values on the fusion line are still the highest, i.e. 72 $\mathrm{HV}$ for UT, $82,8 \mathrm{HV}$ for $12 \mathrm{~h} \mathrm{CT}$, and $96,1 \mathrm{HV}$ for $24 \mathrm{~h}$ CT. A similar trend is also apparently valid for tensile properties (see Table 4). It is unambiguous that changes in the strength values are more or less negligibly small, and the samples soaked at $-140^{\circ} \mathrm{C}$ for about $24 \mathrm{~h}$ have turned into finer and more stable structures than that of samples kept for $12 \mathrm{~h}$.

Although a detailed study has not yet been conducted on the microstructural evaluation, it is believed that detailed changes in the microstructure improve mechanical responses of the present welded samples, where for non-ferrous metals particularly, the effect of sub-zero treatment is still unclear.

\subsection{Microstructure}

Over the years, the term cryogenics has been used to refer to the temperatures around and below $-150^{\circ} \mathrm{C}$, where it has been mostly used to reduce the amount of retained austenite, particularly in tool steels [26,27]. Thus, Kalsi et al. [27] reported that most steels retained 
austenite together with primary and secondary precipitates in the microstructure. Their size and distribution resulted in better mechanical properties, such as wear and fatigue resistances, hardness, and toughness, and also in physical properties (i.e., chemical stability and thermal and electrical conductivity), because sub-zero treatment for soaking time and temperature plays important roles.

Cryogenic treatment has been recently introduced to Al alloys. Although the main mechanisms are still obscure, substantial improvements to mechanical properties are well noticed [28-30]. As a result, several studies on the effects of cryogenics on the behavior of $\mathrm{Al}$ alloys have been recently developed [26,31]. According to the laws of thermodynamics, entropy is zero at absolute zero temperature [32]. Therefore, deep sub-zero treatment is mostly usable relieving internal stresses and strains in the material. When the material is kept at extremely low temperatures for elongated durations, the material tends to reach equilibrium conditions [3235]. It is mostly claimed that microstructure gets finer during the process [36]. Thus, structure at about the welded joint after deep cryogenic treatment can be refined, because there is a great temperature difference during the cryogenic treatment. Internal forces generated during contraction of the bulk create internal stress and so produce some sort of stress concentration in the material. Thus, high-density crystal defect, e.g., dislocations, occurs in the matrix during sub-zero treatment.

In order to reduce the internal energy, dislocations are arranged in such a way that they are mostly aligned and so entrapped along the sub-boundaries. Thus, micro-structure tends to form many fine sub-grains in the matrix forming crystallites and refinement of the grains. As a result, this refined structure contributes to an increase in the strength of the material [37].

Both the sub-structure and elemental distribution become finer during sub-zero treatment. It has been recently noticed that during cryogenic cooling, alloying elements, such as $\mathrm{Mg}$ and $\mathrm{Cu}$, become increasingly dense and fine throughout the matrix [36]. Particularly, ageing process right after cryogenic treatment yields $\mathrm{Mg}$ and $\mathrm{Cu}$ agglomeration at several zones, initially indicating coarse $\mathrm{Mg}$ - and $\mathrm{Cu}$-rich zones that are getting finer and so homogenously distributed within the matrix.

Hence, it is possible to state that during cryogenic treatment, after contraction of the crystal, some of the deformation energies convert into increased internal energy of the alloy. Being now in a meta-stable condition, solid solubility of the alloy is further reduced with decreasing the cryogenic temperature [36]. Thus, for the present material, it is possible to speculate under what condition partial super saturation of the solute elements occurs, where ultra-fine nodules of precipitate of $\beta$ phase $\left(\mathrm{Mg}_{2} \mathrm{Al}_{3}\right)$ emerge, particularly along the sub-grain boundary lines. Thus, during the period of recovering the sub-zero temperature back to the room temperature level by somewhat 'Premature Ageing', the content of ultra-fine $\beta$ phase $\left(\mathrm{Mg}_{2} \mathrm{Al}_{3}\right)$ precipitation possibly takes place in previously-aligned dislocation arrays or networks.

Besides, close to welded joints, tensile strength can be further increased due to the formation of very small $\alpha(\mathrm{Al})$ grains and large specific-surface of grain boundary area. Plus, precipitation of nano-sized dispersed $\beta$ phase plays further roles in the overall strength due to dispersion strengthening. Thus, in the present work, hardness values are considerably higher than those of the sideways material due to the so-called refinement of the structure within the weld zone. The overall strength can obviously be increased by reducing the sub-zero temperature and prolonging the soaking time [37].

In the present work, it has been found that after sub-zero treatment, the samples resting at room temperature condition for one year do not result in any considerable change in the strength of the material. As mentioned earlier, this fact can simply be attributed to the very fine microstructure tailored during the present cryogenic treatment, and its stability against the effect of temperature rises to the level of room conditions. Thus, room temperature level is effective in changing and softening the material, and even keeping it at this level for a long period of time (one year) does not degrade the advanced mechanical strength of this aluminum material.

\section{Conclusions}

The effect of sub-zero treatment on microstructural and mechanical behaviors of the AA5XXX aluminum alloy welded by MIG technique was studied. According to the findings, the following conclusions can be given as follows:

1. Compared to the untreated material (UT), tensile strengths of $12 \mathrm{~h}$ and $24 \mathrm{~h}$ sub-zero temperature treated (CT) specimens increase substantially by $12 \%$ and $14 \%$, respectively. Surprisingly, percentage of elongation on average also extends by $2 \%$, where during the tests, almost all specimens failed from the zone of HAZ and the weld metal;

2. After bending tests, macro and micro cracks are not observed, where the samples are defect-free, particularly at the vicinity of the weld line. This in fact indicates how the joints are well integrated;

3. It is believed that sub-zero treatment significantly refines the microstructure. Thus, to relieve the material from thermal contractions, submicrostructure becomes particularly ultra-fine and 
homogenously distributed, and possibly stabilized by some sort of second-phase precipitation during the recovery periods of sub-zero temperature level;

4. Average strength of the material is, therefore, strongly affected by the cryogenic treatment. On the other hand, there is no significant difference in the overall strength of the material right after the sub-zero treatment and that of the specimens rested for one year at room temperature after CT.

\section{Acknowledgement}

Authors would like to appreciate the support obtained from Gazi University for the Project 07/2011-38.

\section{References}

1. Kurt, A., Uygur, I. and Ates, H. "Effects of temperature on the weldability of powder metal parts joined by diffusion welding", Materials Science Forum, 546549, pp. 667-670, Part: 1-4 (2007).

2. Kurt A. and Ates, H. "Investigation of weldability of P/M bronze materials by TIG welding technique", Advanced Materials Research, 23, pp. 315-318 (2007).

3. Kurt, A., Uygur, I. and Ates, H. "Effect of porosity content on the weldability of powder metal parts produced by friction stir welding", Materials Science Forum, 534-536, pp. 789-792 (2007).

4. Kurt, A., Ates, H. and Durgutlu, A. "Exploring the weldability of powder metal parts", Welding Journal, 83(12), pp. 34-37 (2004)

5. Kammer, C. "Fundamental and materials", Aluminum Handbook, 1, ISBN 978-3-410-22023-7 (1999).

6. Aluminum Association Website, http://www. Aluminum.org

7. Global Aluminum Industry Sustainability Performance 2010, International Aluminum Institute (2011).

8. Tabereaux, A.T. and Peterson, R.D. "Aluminum production", in Treatise on Process Metallurgy, pp. 839917 (2014).

9. Ates, H. and Kaya, N., "Effect of friction time on microstructure and mechanical properties of friction welded AISI 304 stainless steel to AISI 1060 steel", Metallofizika I Noveishie Tekhnologii, 35(2), pp. 241252 (2013).

10. Ates, H. "Investigation of joining interface of dissimilar steels by friction welding technique", Metallofizika I Noveishie Tekhnologii, 30(7), pp. 1009-1020 (2008).

11. Cicek, A., Kivak, T., Uygur, I., Ekici, E. and Turgut, Y. "Performance of cryogenically treated M35 HSS drills in drilling of austenitic stainless steel", Int. J. Adv. Manuf. Technol., 73, pp. 60-65 (2012).

12. Cicek, A., Uygur, I., Kivak, T. and Ozbek, N.A. "Machinability of AISI 316 austenitic stainless steel with cryogenically treated M35 High-speed stell twist drills", J. Manuf. Sci. \& Eng., 134, pp. 1-6 (2012).
13. Ikeda, K., Aoki, M., and Shirakura, T. Light Metal, 23, pp. 393-8 (1973).

14. Ishchenco, A.Y. and Novikov, N.V. "Advances in cryogenic engineering", 24, New York Plenum Press, pp. 491-504 (1978).

15. Calcraft, R.C., Wahab, M.A., Viano, D.M., Schumann, G.O., Phillips, R.H. and Ahmed, N.U. "The development of the welding procedures and fatigue of buttwelded structures of aluminium-AA5383", J. Mater. Process. Technology, 92-93, pp. 60-65 (1999).

16. Luijendijk, T. "Welding of dissimilar aluminum alloys", J. Mater. Process Technology, 103, pp. 29-35 (2000).

17. Krishnakumar, S. and Weidong, W. "Effect of welding and weld repair on crack propagation behavior in aluminum alloy 5083 plates", Materials and Design, 23, pp. 201-208 (2002).

18. Bertini, L., Fontanari, V. and Straffelini, G. "Influence of post weld treatments on the fatigue behavior of A1alloy welded joints", Int. J. Fatigue, 20(10), pp. 749755 (1998).

19. Chen, D.L. and Chaturvedi, M.C. "Effects of welding and weld heat affected zone simulation on the microstructure and mechanical behavior of a 2195 aluminum-lithium alloy", Met. Mat. Trans. A, 32A, pp. 2728-41 (2001).

20. Uygur, I. and Dogan, I. "The effect of TIG welding on microstructure and mechanical properties of a buttjoined unalloyed titanium", Metalurgija, 44(2), pp. 119-123 (2005).

21. http://www.aws.org/files/205/2009011/AWSPHB 2. PDF

22. Uygur, I. and Gulenc, B. "The effect of shielding gas composition for MIG welding process on mechanical behavior of low carbon steel", Metalurgija, 43(1), pp. 35-40 (2004).

23. Effects of Cryogenic Treatment on the Residual Stress and Mechanical Properties of an Aerospace Aluminum Alloy

https://archive.org/details/nasa_techdoc_20010067299 (Feb. 1, 2001)

24. Baughurst, L. and Voznaks, G. "Welding defects, causes and correction", Australian Bulk Handing Review, pp. 26-29 (July/August 2009).

25. Arslan, Y., Uygur, I. and Bayraktar, H. "An investigation of cryogenic treated cold work steel punch performance for AISI 304 stainless steel sheets", $J$. of Advanced Technology Sciences, 2(3), pp. 61-75 (in Turkish) (2013).

26. Panigrahi, S.K. and Jayaganthan, R. "Development of ultrafine grained high strength age hardenable Al 7075 alloy by cryorolling", Mater. \& Des., 32, pp. 3150-3160 (2011).

27. Kalsi, N.S., Sehgal, R. and Sharma, V.S. "Cryogenic treatment of tool materials", Mater. Manufac. Proces., 25, pp. 1077-1100 (2010). 
28. Reed, R.P. and Golda, M. "Cryogenic composite supports: a review of strap and strut properties", Cryogenics, 37, pp. 233-250 (1997).

29. Bensely, A., Prabhakaran, A., Lal, D.M. and Nagarajan, G. "Enhancing the wear resistance of case carburized steel (En 353) by cryogenic treatment", Cryogenics, 45, pp. 747-754 (2005).

30. Darwin, J.D., Lal, D.M. and Nagarajan, G. "Optimization of cryogenic treatment to maximize the wear resistance of 18 by Taguchi method", J. Mater. Process. Tech., 195, pp. 241-247 (2008).

31. Woodcraft, A.L. "Predicting the thermal conductivity of aluminum alloys in the cryogenic to room temperature range", Cryogenics, 45, pp. 421-431 (2005).

32. Patıl, P.I. and Tated, R.G. "Comparison of effects of cryogenic treatment on different types of steels", I.J. of Computer Applications, ICCIA, pp. 1-21 (2012).

33. Collins, D.N. and Dormer, J. "Deep cryogenic treatment of a D2 cold-work tool steel", Heat Treat. Met., 24, pp. 71-74 (1997).

34. Yun, D., Lın, X.P. and Xiao, H.S. "Deep cryogenic treatment of high-speed steel and its mechanism", Heat Treat. Met., 25(3), pp. 55-59 (1998).

35. Lal, D.M., Renganarayanan, S. and Kalanidhi, A. "Cryogenic treatment to augment wear resistance of tool and die steel", Cryogenics, 41, pp. 149-155 (2001).

36. Taskesen, A., Aksoz, S. and Özdemir, A.T. "Effect of cryogenics on ageing behavior of B4C reinforced 7075 aluminum composites", Kovove Materialy - Metallic Materials, 55, pp. 57-67 (2017).

37. Shan, G., Zhisheng, W., Pengfei, J., Junjie, W. and Peng, S. "Effect of deep cryogenic treatment on microstructure of 5A06 aluminum alloy MIG welded joint", Materials Science Forum, 724, pp. 182-185 (2012).

\section{Biographies}

Hakan Ates Associate Professor was born in Ankara in 1971. He is an Associate Professor in Gazi University, Department Metallurgical and Materials Engineering. $\mathrm{He}$ is an international welding engineer and international welding inspector (comprehensive level). He is also vice manager of the Gazi KABTEM application and research center. He has memberships to KATED (Welding Technology Society) and TPMA (Turkish Powder Metallurgy Association). He has many papers on powder metallurgy and welding processes.

Abbas Tamer Özdemir received BSc and MSc degrees from Middle East Technical University (METU). His $\mathrm{PhD}$ is from the Open University, UK. Since 1995, he has been a lecturer in Gazi University. He is a Professor in the field of Materials Engineering, mostly indulged in Physical and Mechanical Metallurgy. He is currently working in the fields of composite materials, cryogenics, and residual stresses.

Mustafa Uzun was born in Amasya in 1983. He works for T.C. Prime Minister General Directorate of Foundations. In 2008, He graduated from University of Eskişehir Osmangazi. He studied reinforced concrete and steel structures, and received his master degree in 2014 from Gazi University.

Ilyas Uygur was born in 1969 in Balikesir. He currently works at Duzce University. He is the Dean of the Engineering Faculty. He is also manager of universityindustry partnership in Duzce. His main research areas include fatigue, wear, powder metallurgy, composites, welding, and machinability of materials. 